Alpha Contamination Assessment for DED Activities: Monitoring Pipe Interiors

$$
\begin{aligned}
& \text { ZECEIVED } \\
& \text { FEB } 281996 \\
& \text { OSTI }
\end{aligned}
$$

Los Alamos

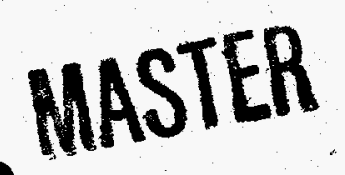

NATIONAL LABORATORY

Los Alamos National Laboratory is operated by the University of California for the United States Department of Energy under contract W-7405-ENG-36.

DISTRIBUTION OF THS DOCUAERT IS WNLMTED 
Edited by Paul W. Henriksen, Group CIC-1

An Affirmative Action/Equal Opportunity Employer

This report ans prepared as an account of work sponsored by an agency of the United States Government. Neither The Regents of the University of California, the United States Government nor any agency thereof, nor any of their employees, makes any warranty, express or implied, or assumes any legal liability or responsibility for the accuracy, completeness, or usefulness of any information, apparatus, product, or process disclosed, or represents that its use would not infringe privately owned rights. Reference herein to any specific commercinl product, process, or service by trade name, trademark, manufacturer, or otherwise, does not necessarily constitufe or imply its endorsement, recommendation, or favoring by The Regents of the University of Californin, the United States Government, or any agency thereof. The views and opinions of authors expressed herein do not necessarily state or reflect those of The Regents of the University of Californin, the United States Government, or any agency thereof. The Los Alamos National Laboratory strongly supports academic freedom and a researcher's right to publish; therefore, the Laboratory as an institution does not endorse the viewopint of a publication or guarantee its technical correctness. 
UC-940

Issued: February 1996

Alpha Contamination Assessment for DED Activities:

Monitoring Pipe Interiors

M. W. Rawool-Sullivan

J. G. Conaway

D. W. MacArthur

J. Vaccarella 



\title{
ALPHA CONTAMINATION ASSESSMENT FOR D\&D ACTIVITIES: MONITORING PIPE INTERIORS
}

\author{
by \\ M. W. Rawool-Sullivan, J. G. Conaway, D. W. MacArthur, \\ and J. Vaccarella
}

\begin{abstract}
We have developed a prototype instrument capable of assessing alphaemitting contamination on interior surfaces of ducts, pipes, tanks, and other enclosed volumes without inserting a probe. Air is drawn through the potentially contaminated volume and then through a detection grid, where ions created in the air by alpha particles are collected and the resulting charge measured with a sensitive electrometer. A filter at the intake end of the contaminated volume excludes externally created ions, so only ions generated inside the volume are detected. We have studied the response of this prototype in initial experiments using calibrated alpha sources with various pipe diameters and configurations, air flows, and source locations in the pipes. The results of these experiments indicate that this method can be an effective approach to assessing internal contamination.
\end{abstract}


Many DOE facilities have ducts, pipes, tanks, and other enclosed volumes that are internally contaminated with radionuclides. Because alpha particles cannot penetrate pipe walls, assessment of this internal contamination with conventional instruments requires a sensor to be inserted into the enclosed volume and slowly moved along all surfaces. Even under the best of conditions, this approach can be tedious and may spread contamination. In the case of smalldiameter or curved pipes and other complex or inaccessible enclosed volumes, this approach to internal monitoring is impractical.

Long Range Alpha Detector (LRAD) technology offers unique advantages for monitoring enclosed volumes such as pipe interiors. Unlike conventional alpha detectors, LRAD-based instruments do not need to be in close proximity to the alpha sources to provide a sensitive measurement. ' By drawing air through the enclosed space using externally mounted fans, the ions are transported to an electrode; the resulting charge is measured by a sensitive electrometer. Most gases can be used for ion transport, so pipes and ducts filled with air or various gases can be monitored effectively.

\section{MONITORING PIPES AND DUCTS}

\section{Mechanical considerations}

A conceptual diagram of the system in operation is shown in Fig. 1. The filter at the intake end of the contaminated volume prevents ions from entering the volume being investigated, so only ions generated inside the volume being assessed are detected. In our experiments we used a $3 \mathrm{M}$ Filtrete ${ }^{\mathrm{TM}}$ filter (G-100) for sources below $5000 \mathrm{dpm}$. For substantially stronger sources, a filter is generally unnecessary because the signal will be much higher than the background unless the air is highly contaminated. A photograph of the grid in the single-grid pipe monitor is shown in Fig. 2. 


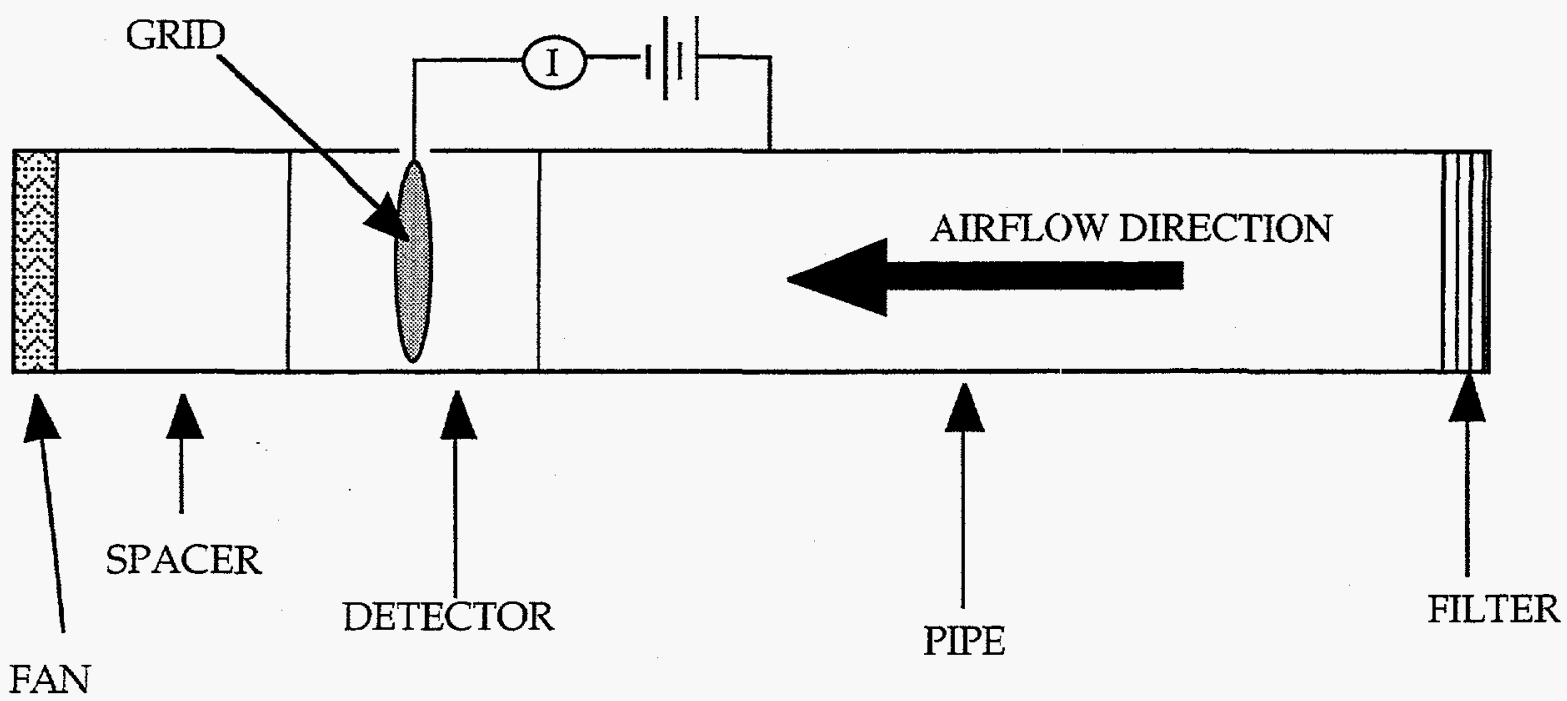

Figure 1 : Schematics of pipe monitoring test set-up

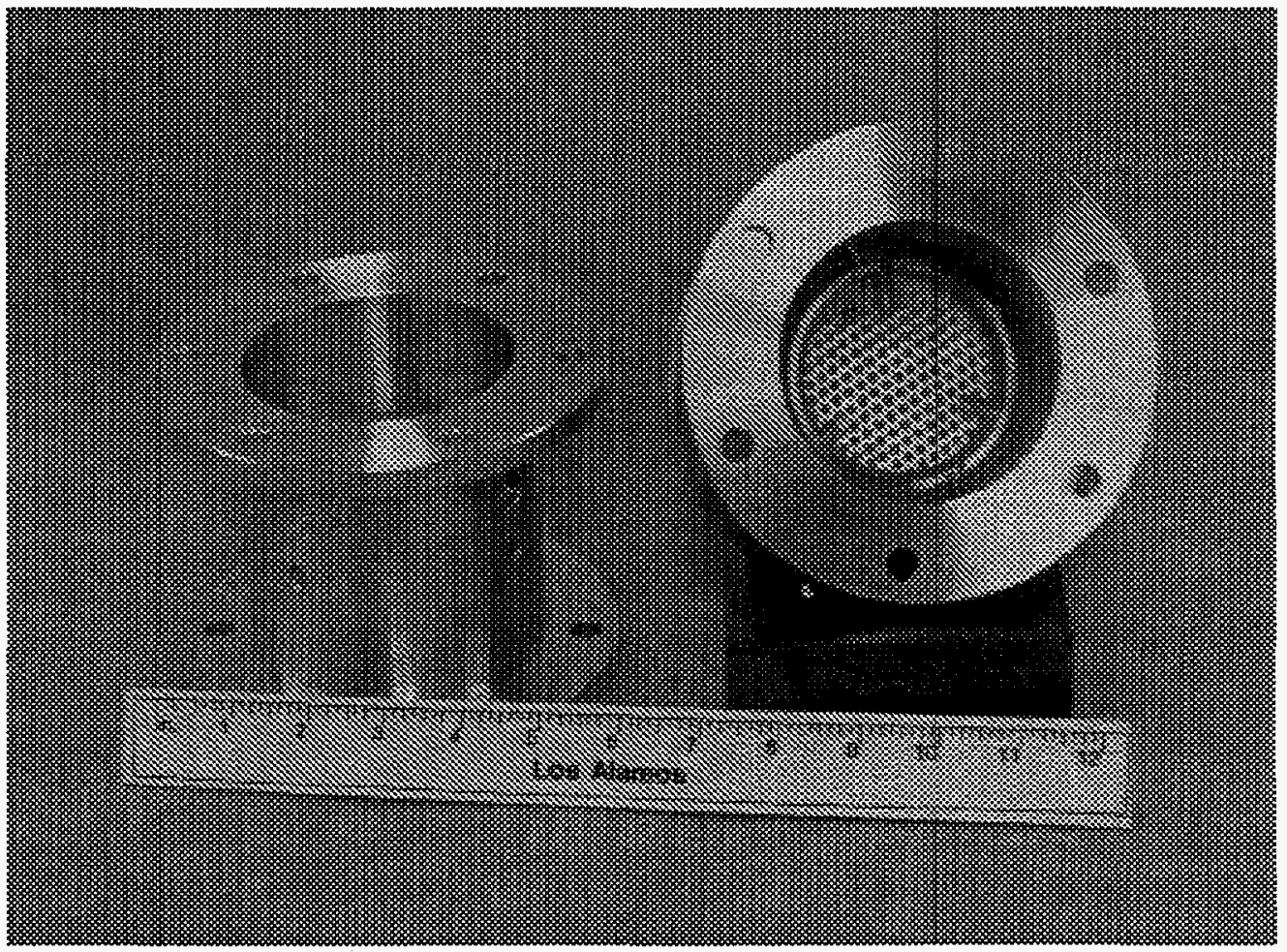

Figure 2. Photograph of the 9-cm single-grid pipe monitor. 
We studied the use of a 15-cm spacer between the fan and the detector to prevent back draft from the fan from affecting the collection of the ions at the grid and thereby lowering the response. The response from the detector when the spacer was present between the fan and the detector was higher and less noisy than when the spacer was absent (Fig. 3). To ensure laminar flow we filled this spacer with conventional drinking straws for these experiments.

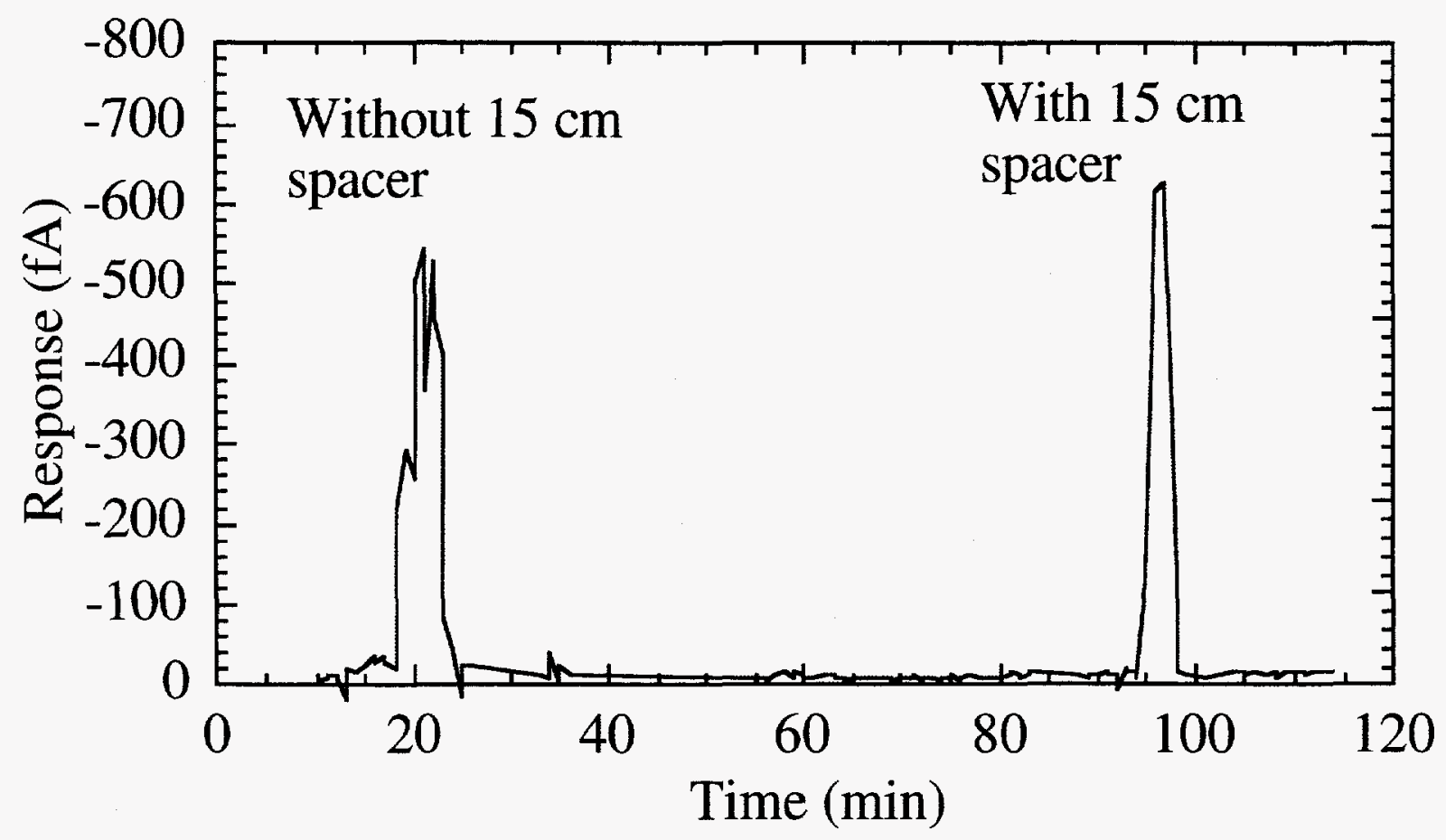

Figure 3. Change in the response due to addition of a cylindrical spacer.

\section{Response as a function of voltage}

The response of the prototype $9-\mathrm{cm}$ diameter pipe monitor as a function of voltage was measured using a 9-cm diameter straight aluminum pipe, $6 \mathrm{~m}$ in length. A diagram of the experimental setup was shown earlier in Fig. 2. For this test we placed a ${ }^{238} \mathrm{Pu}$ source (rated by the manufacturer at $218,000 \mathrm{dpm}$ ) in the pipe some $5.5 \mathrm{~m}$ away from the detector. Air speed measured $15 \mathrm{~cm}$ from the grid was kept constant at approximately $0.9 \mathrm{~m} / \mathrm{s}(0.35 \mathrm{~m} / \mathrm{min})$; the effect of air speed on detector response is considered later in this report. The instrument response is shown in Fig. 4 , where instrument response in fempto-amps $\left(10^{-15} \mathrm{~A}\right)$ is plotted against applied voltage. This figure shows that the sensitivity of the instrument increases with increasing applied voltage, nearly leveling off at applied voltages above roughly $500 \mathrm{~V}$. In the past we have generally used commercially available $300 \mathrm{~V}$ batteries; Fig. 4 shows that with these batteries, the detector will yield approximately $80 \%$ of the available sensitivity. 


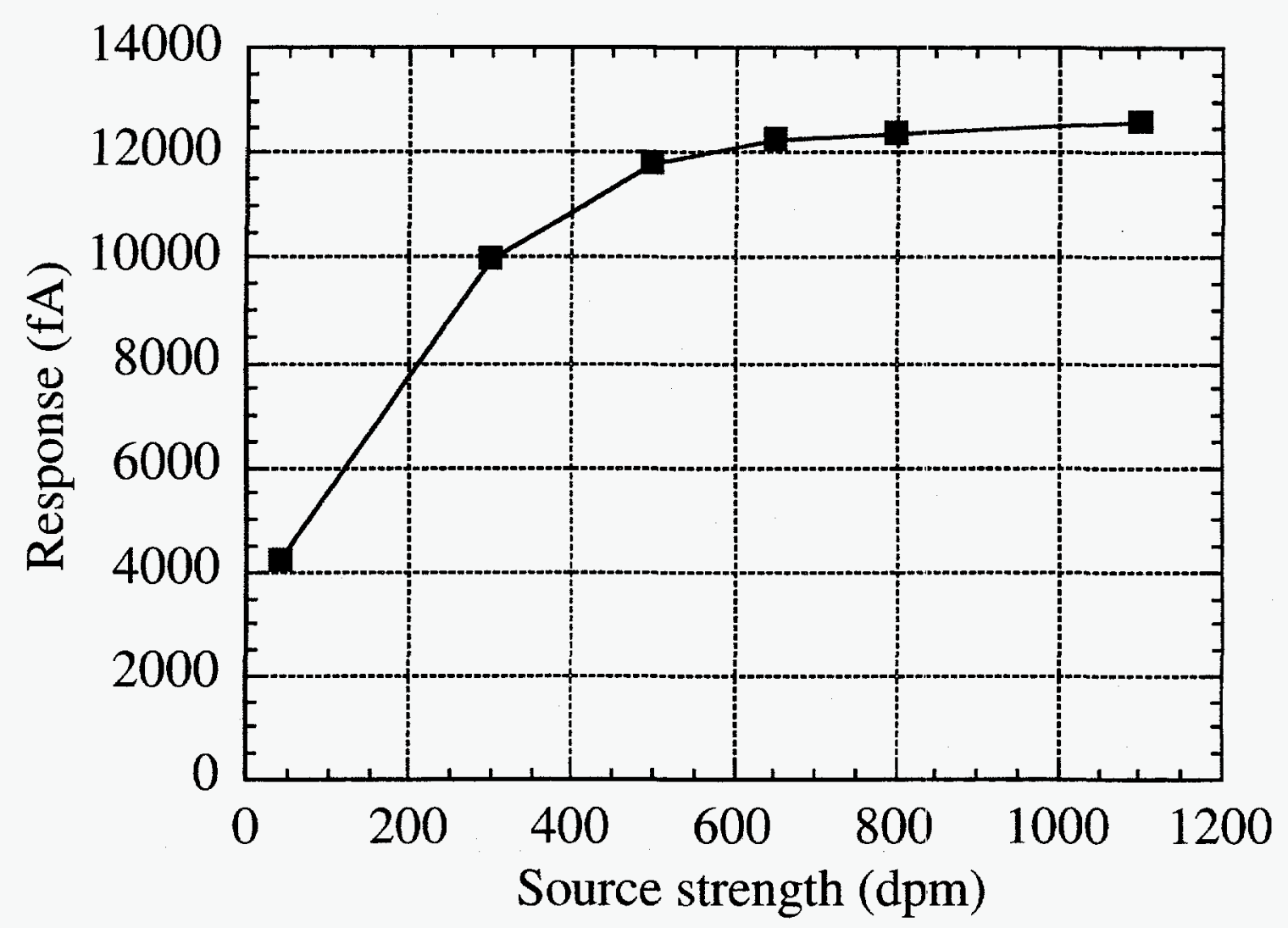

Figure 4: Response of the 3.5-in. ( 9-cm) pipe monitor when attached to a 20-ft $(\sim 600 \mathrm{~cm})$ long pipe as a function of voltage. The error bars are smaller than the symbols, and the lines are intended to guide the eye only.

\section{Response as a function of source position}

Experiments were performed to determine how the instrument response varied as a function of distance between the grid and the source within the pipe. The results for four different source strengths are shown in Fig. 5, where it is evident that instrument response drops steadily with increasing distance to the source. This plot shows that instrument response signals can be separated out even at the distance of $5.5 \mathrm{~m}(18 \mathrm{ft})$. It is our observation that most of the ion losses are caused by interactions with the pipe walls. 


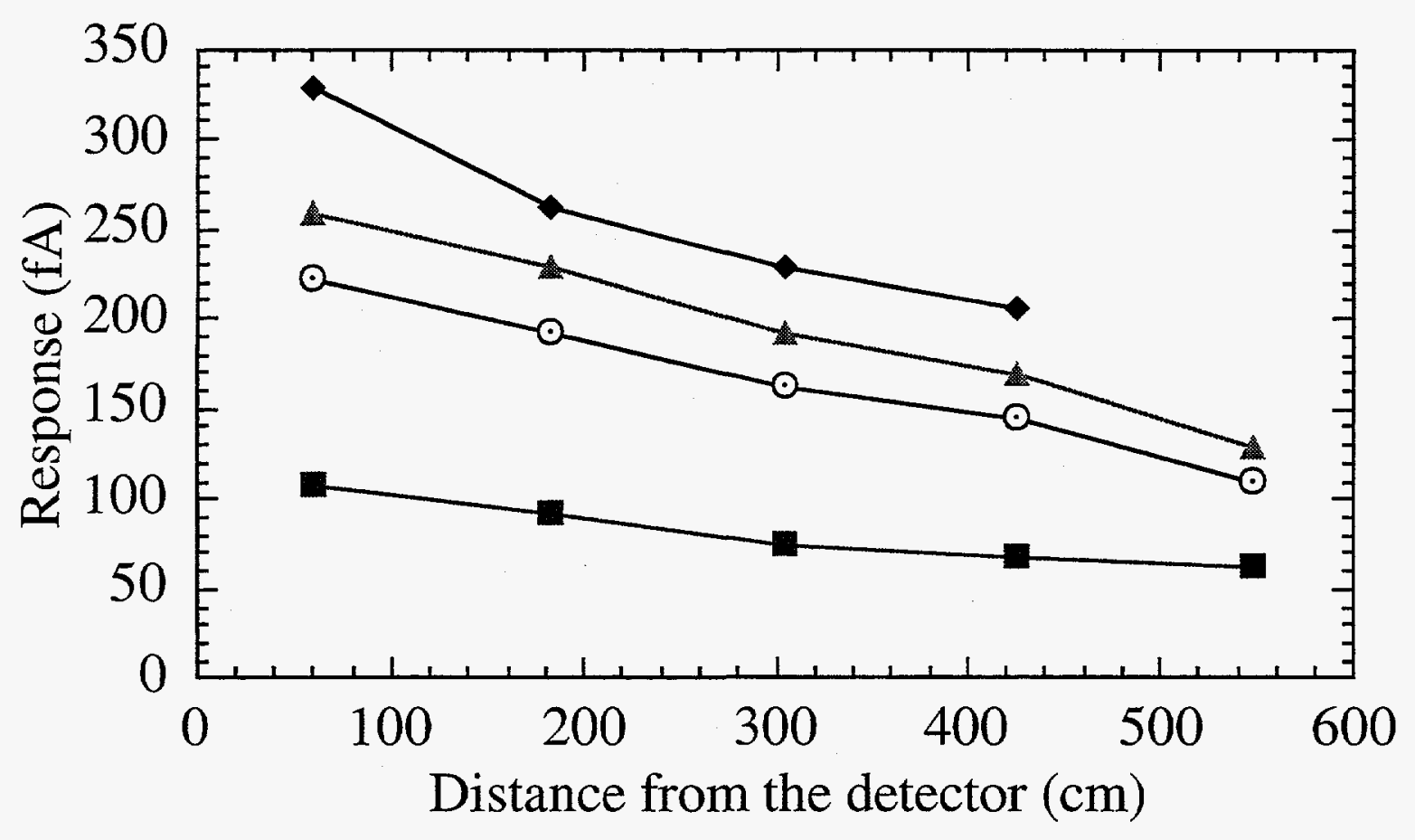

$\rightarrow 1000 \mathrm{dpm}-2500 \mathrm{dpm} \multimap 3250 \mathrm{dpm} \multimap 4350 \mathrm{dpm}$

Figure 5. Instrument response as a function of distance between source and detector.

We used data taken using a nominal $218,000 \mathrm{dpm}$ source to calculate the lifetime of the ions for these conditions. Here we define ion lifetime as the time (distance/air speed) at which the response falls to half the value of the number of ions obtained when the source is placed directly next to the grid inside the pipe. For this analysis we have drawn no distinction between various possible modes of ion loss. For $0.9 \mathrm{~m} / \mathrm{s}$ air flow $\left(\sim .35 \mathrm{~m}^{3} / \mathrm{min}\right)$, the lifetime of the ions was 8.4 sec. Figure 6 shows one such plot of the ion lifetime and a fit obtained using the function $N=$ $N_{0} /[1+(t / \tau)]$, where $N_{0}$ is the initial number of ions, $\tau$ is the lifetime of the ions and $t$ is the time; this equation is derived from Knoll. ${ }^{2}$ 


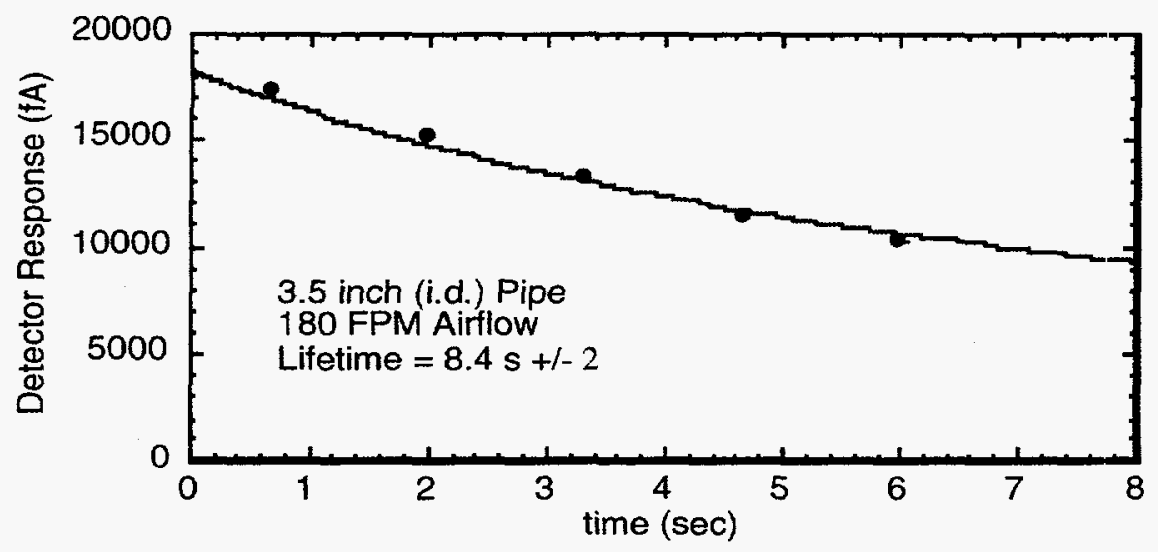

Figure 6: Lifetime of ions within the pipe.

\section{Response as a function of air speed}

To determine how ion lifetime varies as a function of air velocity, we performed experiments in which grid voltage and source strength were kept constant and air velocity was varied. Figure 7 shows the results for an experiment with $300 \mathrm{~V}$ applied to the grid and a nominal $218,000 \mathrm{dpm}$ ${ }^{238} \mathrm{Pu}$ source. In this experiment, the highest response was obtained with an air velocity of 0.9 $\mathrm{m} / \mathrm{s}$; system response was lower both at the higher air velocity of $2 \mathrm{~m} / \mathrm{s}$ and the lower air velocity of $0.46 \mathrm{~m} / \mathrm{s}$. It appears that loss of ions to the pipe walls and other effects reduces the response at lower velocities, while the ions are carried through the detector too quickly to allow complete collection on the grid at higher velocities. We propose to use parallel grid plates that are extended along the direction of air flow (a "venetian blind" design) to increase instrument response at higher air velocities (patent applied for). The use of higher air velocities should decrease the loss of ions in transit between distant sources and the detector, allowing longer or smaller diameter pipes and ducts to be investigated. Earlier tests using the LRAD-based large object monitor fitted with a parallel plate venetian blind grid showed increased detection efficiency with extended grid plates (J. A. Bounds, private communication). 


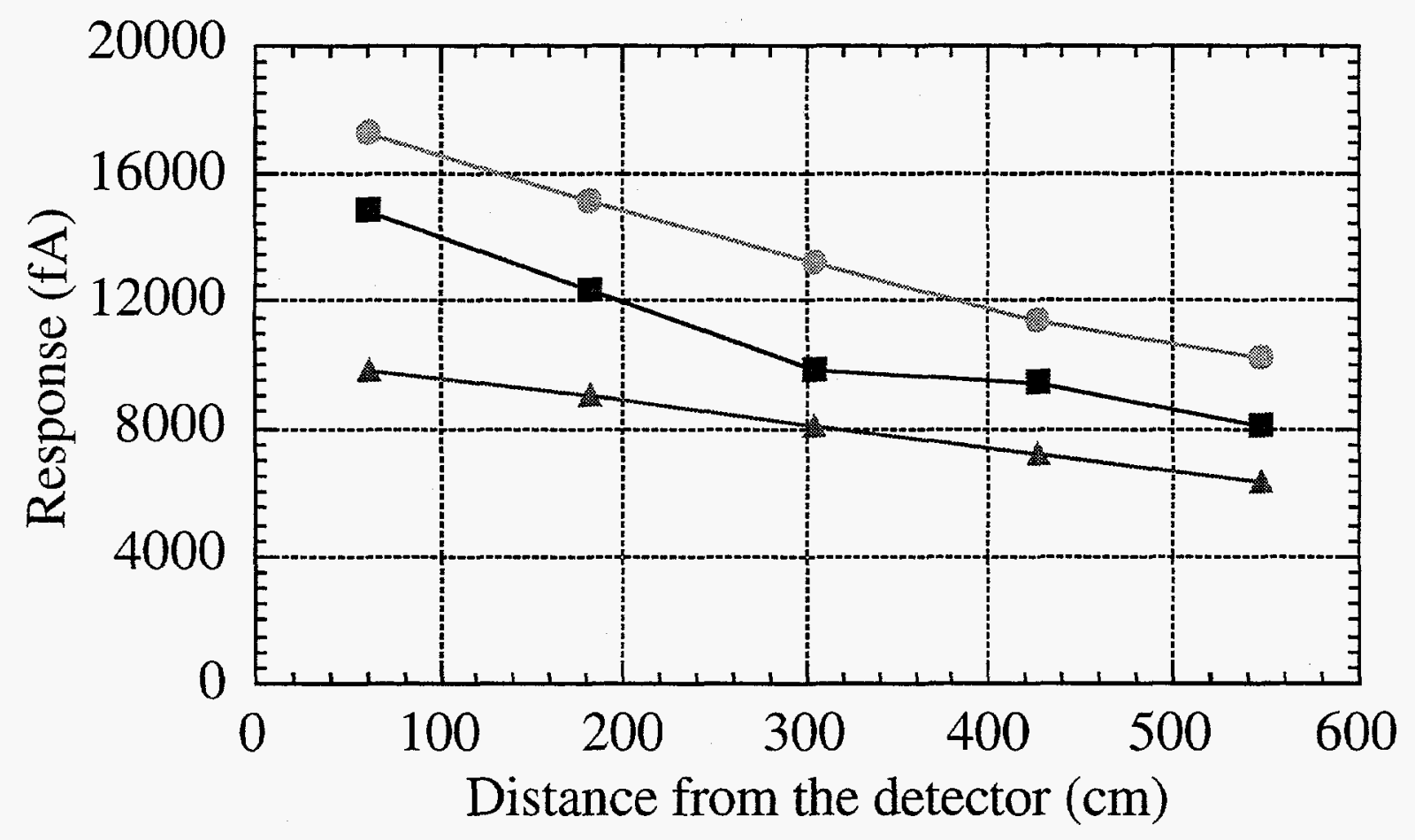

$\rightarrow 90 \mathrm{fpm} \rightarrow 180 \mathrm{fpm} \rightarrow 400 \mathrm{fpm}$

Figure 7. Instrument response at $300 \mathrm{~V}$ as a function of distance between the source and detector, for various air velocities.

Figure 8 shows the results of a similar experiment using a grid voltage of $525 \mathrm{~V}$ and the same $218,000 \mathrm{dpm}$ source. Here, air velocity was varied from 0.7 to $1.2 \mathrm{~m} / \mathrm{s}$. The results show an increase in instrument response with air velocity. We did not reach a maximum response as a function of air velocity in this experiment, unlike the results shown in Fig. 7. 


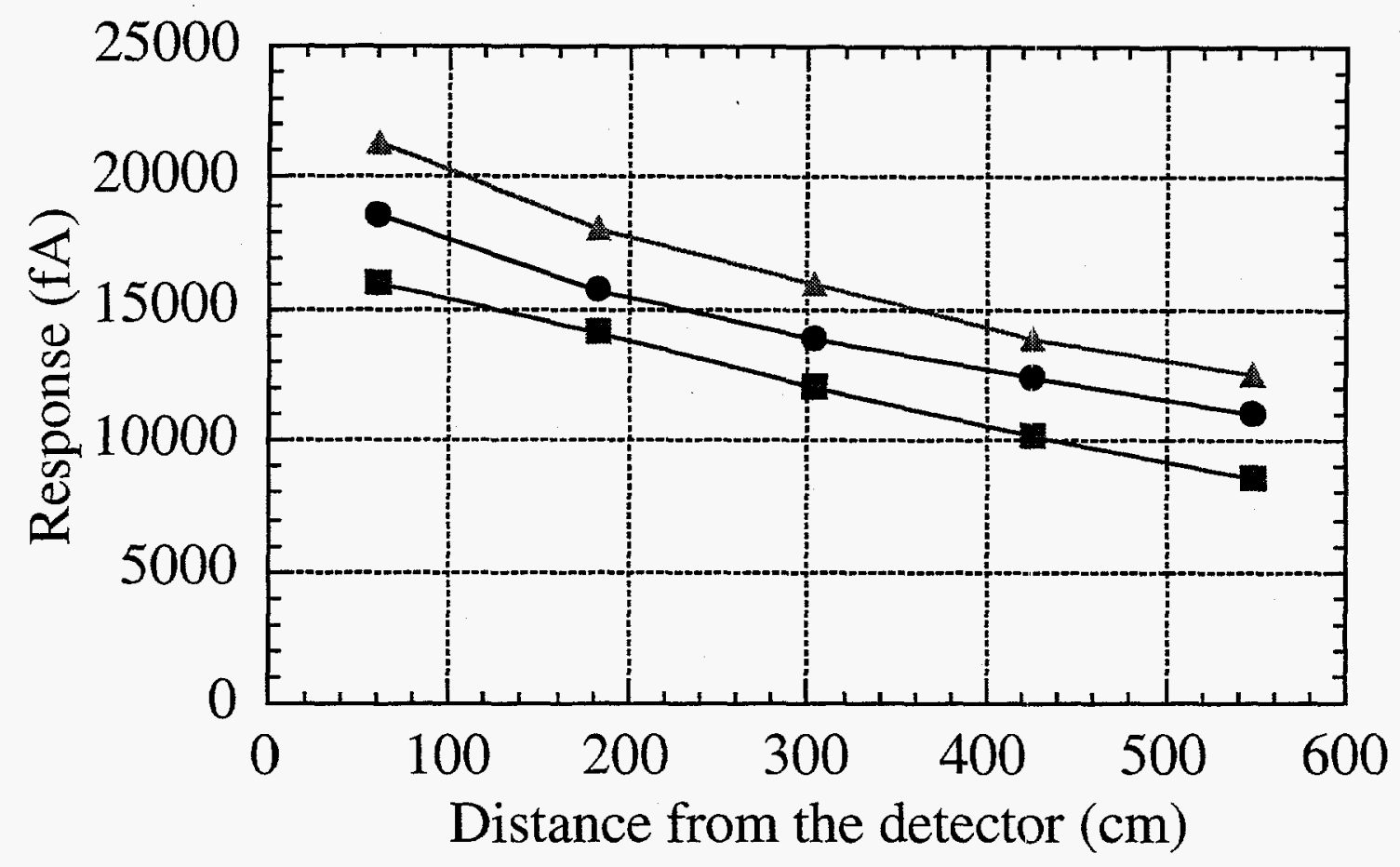

$$
\rightarrow 140 \mathrm{fpm} \rightarrow 180 \mathrm{fpm} \rightarrow 230 \mathrm{fpm}
$$

Figure 8. Instrument response at $525 \mathrm{~V}$ as a function of distance between the source and detector, for various air velocities.

\section{Response with a $90^{\circ}$ bend in the pipe}

Experiments were performed with the same ${ }^{238} \mathrm{Pu}$ source of $218,000 \mathrm{dpm}$ strength placed at four different positions in a $9-\mathrm{cm}$-diameter aluminum pipe with a $90^{\circ}$ bend. The pipe was made up of two $60-\mathrm{cm}$ straight sections joined by a $90^{\circ}$ bend section. The grid voltage was $300 \mathrm{~V}$ and the air velocity was $0.9 \mathrm{~m} / \mathrm{s}(\sim .35 \mathrm{~m} / 3 / \mathrm{min}$ air flow). Instrument response as a function of source position is shown in Fig. 9. Comparing with the data from the straight pipe of the same diameter, it can be seen that the decrease in the response between $60 \mathrm{~cm}$ and $80 \mathrm{~cm}$ is due mainly to the increased distance between the detector and the source rather than due to the bend in between. This observation is important for monitoring bent pipes or process equipment. 


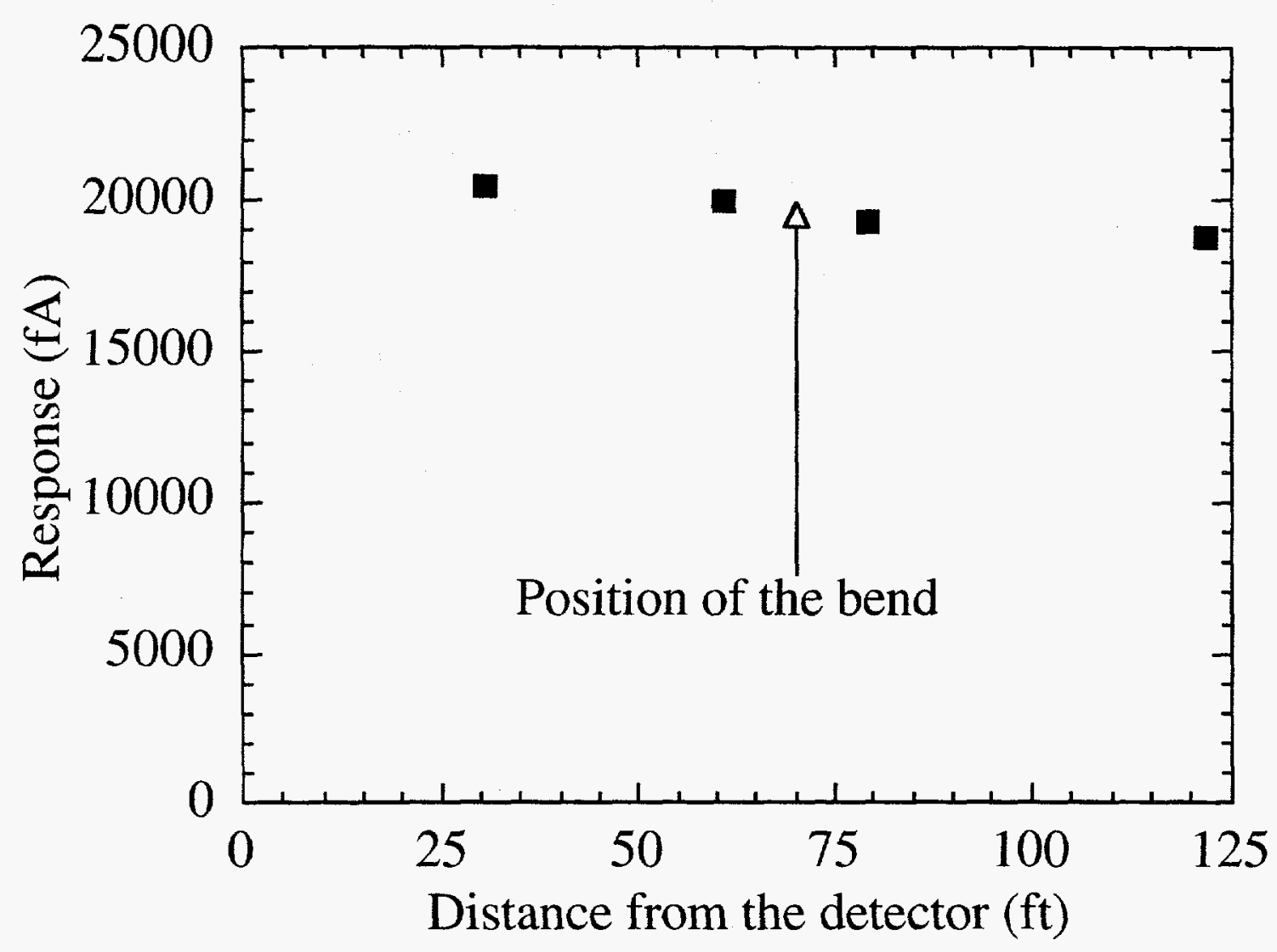

Figure 9: Response in a bent pipe

\section{Determining the location of the source within the pipe}

Currently we are investigating two ways of determining the location of a source within a pipe. The first method is to shutter the fan and see how long it takes for the signal to reach the grid. Source distance can be calculated from this time measurement for a given air speed. The accuracy of this source position estimate will depend largely on the time resolution of our data acquisition system and accuracy of the airflow measurement. The second method involves making measurements at both ends of the same pipe and comparing the results. This method makes use of the fact that the response falls as a function of distance between the source and the detector. In the preliminary laboratory tests both of these methods appeared promising but need further work. ${ }^{3}$

\section{Conclusion}

In conclusion, the results presented here strongly suggest that, with further development, we can provide nondestructive, in situ and real time measurements of alpha-emitting contaminants within pipes, both straight and curved. Localization of the contamination in the pipe also appears to be feasible. 


\section{References}

1. J. G. Conaway, M. W. Rawool-Sullivan, and D. W. MacArthur, "Alpha Contamination Assessment for D\&D Activities, Part 1: Technology Overview." Los Alamos National Laboratory report LA-13062-MS.

2. G. F. Knoll, Radiation Detection and Measurement 2nd ed. (New York: John Wiley \& Sons, Inc., 1989), pp. 131-132.

3. M. W. Rawool-Sullivan, "Alpha Characterization Inside Pipes Using Ion-Transport Technology: Progress Report 12/94," Los Alamos National Laboratory document LA-UR94-4369. 
